\title{
Effect of steel fibres dosage in alkali-activated slag mortar on acoustic emission obtained during three-point bending tests
}

\author{
Libor Topolá r̆ $^{1,}$, Hana Šmonová ${ }^{1}$, Pavel Schmid ${ }^{1}$ and Pavel Rovnaník ${ }^{1}$ \\ ${ }^{1}$ Brno University of Technology, Faculty of Civil Engineering, Veveři 331/95, Brno 602 00, Czech \\ Republic
}

\begin{abstract}
The acoustic emission phenomenon is directly associated with nucleation of cracks in structural materials during loading. This paper analyses acoustic emission signals captured during three-point bending fracture tests of alkali-activated slag mortar specimens with different amount of steel fibres. Typical parameters of acoustic emission signals were identified for different mixtures to further describe the under-thestress behaviour and failure development. The acoustic emission signals from crack growth were continuously monitored using acoustic emission sensors mounted on the specimen surface. Acoustic emission results are accompanied by selected mechanical fracture parameters determined via evaluation of load versus displacement diagrams recorded during threepoint bending tests.
\end{abstract}

\section{Introduction}

Alkali-activated binders are relatively new binders, alternative to the conventional Portland cement, formed through the alkaline activation of different industrial by-products such as blast furnace slag and fly ash. In last two decades, alkali-activated cement and concrete have attracted attention all over the world due to their benefit of low energy cost and good durability compared to Portland types of cement $[1,2]$.

The composites based on alkali-activated slag are quasi-brittle materials with low tensile strength properties. This negative property can be changed by the inclusion of short discrete fibres into the matrix which prevent or control initiation, propagation, or coalescence of microcracks [3, 4]. Steel, glass, carbon, wooden, synthetic and natural fibres are used for this functionality. Addition of fibres to the brittle concrete or mortar can improve many of its technical features (e.g. tensile strength, flexural strength, fracture toughness, resistance to fatigue, impact, wear and thermal shock) $[4,5]$.

Addition of fibres is also an efficient method to improve shrinkage behaviour of alkaliactivated slag based composites $[6,7]$. The most significant effect of fibres is a prevention of microcracks from the propagation in composites. The extension and propagation of microcracks that occur due to the internal stresses in concrete are forestalled by stress transfer capability of randomly distributed fibres. According to their shape and quantity,

*Corresponding author: libor.topolar@,vutbr.cz 
fibres carry some of the stress that occurs in the matrix itself and transfer the other part of the stress to the stable cement matrix [8-10].

\section{Experimental methods}

\subsection{Materials and specimen preparation}

Five different mixtures of alkali-activated slag mortars were prepared (Table 1). The first one was reference without addition of fibres. The others contain the steel fibres in amount $5,10,15$ and $20 \%$ from the weight of the slag. The mean length of steel fibres was $6 \mathrm{~mm}$ and mean diameter was $0.17 \mathrm{~mm}$. The mixtures were cast into $40 \times 40 \times 160 \mathrm{~mm}$ prismatic moulds and left to set. The hardened specimens were immersed in water for 27 days, then pulled out of water and allowed to dry spontaneously under ambient conditions for 24 hours prior to three-point bending test.

Table 1. Mixture proportions of alkali-activated slag composites.

\begin{tabular}{|c|c|c|c|c|c|}
\hline Mixture component & REF & D_05 & D_10 & D_15 & D_20 \\
\hline Slag [g] & 450 & 450 & 450 & 450 & 450 \\
\hline Sodium silicate [g] & 90 & 90 & 90 & 90 & 90 \\
\hline Aggregate [g] & 1350 & 1350 & 1350 & 1350 & 1350 \\
\hline Water [ml] & 185 & 190 & 190 & 195 & 195 \\
\hline Steel fibres [g] & - & 22.5 & 45 & 67.5 & 90 \\
\hline
\end{tabular}

\subsection{Testing methods}

\subsubsection{Acoustic emission method}

Acoustic emission (AE) method is a non-destructive technique that is used to monitor damage mechanism in composites [11]. It is known that increasing cracks give rise to AE activity which can be recorded using sensors mounted on the surface of the composites under investigation. The degree of damage and the characteristics of received signals are strongly dependent on the damage process and enable the monitoring of composite behaviour during the fracture test [12]. The universal measurement and diagnostic system $\mathrm{DAKEL}-\mathrm{XEDO}^{\odot}$ (made by ZD Rpety-Dakel company) was used for the AE measurements. The guard sensors eliminate noise that is generated from outside the area of interest. In this work, four acoustic MIDI emission sensors (type IDK-09) were used, all having identical frequency range and being attached to the surface by beeswax (Figure 1).

\subsubsection{Fracture test procedure}

Three-point bending tests were carried out on a LabTest 6-1000.1.10 multi-purpose mechanical testing machine with the measuring range $0-1000 \mathrm{kN}$ at a laboratory centre AdMaS, Faculty of Civil Engineering, Brno University of Technology. The beam specimens with central notch were tested in three-point bending configuration. The initial central notch was cut before testing by diamond blade saw, depth of notch was approximately $1 / 3$ of the depth of specimen (Fig. 1). A load-displacement (deflection in the middle of span length) $F-d$ diagram was recorded during testing and consequently used for the determination of elasticity modulus $E$ from the first (almost linear) part of the $F-d$ diagram, and for the calculation of effective fracture toughness $K_{I c}$ and specific fracture energy $G_{F}{ }^{*}$ values. The effective fracture toughness value was determined using the 
Effective Crack Model [13], which combines the linear elastic fracture mechanics and crack length approaches. An estimate of fracture energy was obtained from the $F-d$ diagram according to the RILEM method (using the work-of-fracture value) [14]. Informative compressive strength $f_{c}$ values were also determined for all specimens on the fragments remaining after the fracture experiments had been performed.

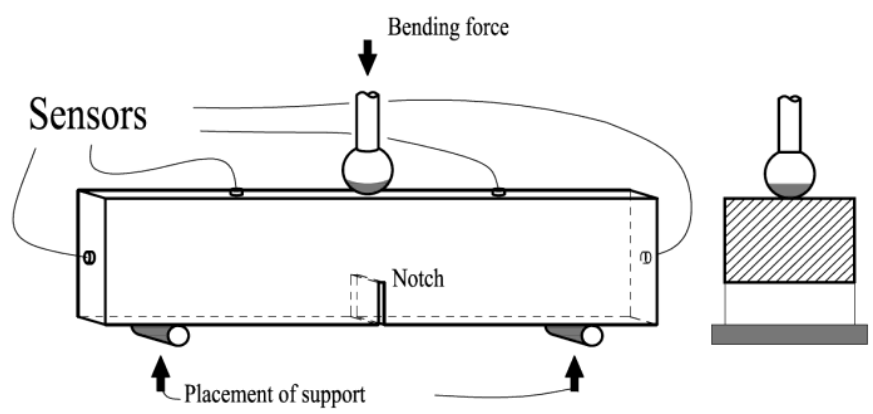

Fig. 1. The arrangement of experiment with placement of acoustic emission sensors on specimen during the three-point bending test.

\section{Results}

\subsection{Acoustic emission method}

To describe AE signals which are formed during the three-point bending test in the specimens, we focused our attention on the number of AE events and amplitude of these signals. The number of times the signal rises and crosses the threshold is the number of the $\mathrm{AE}$ events. The second observed parameter is amplitude of AE signals, which is the greatest voltage measured in a waveform. This is a very important parameter in AE inspection because it determines the detectability of the signal. Signals with amplitudes below the operator-defined minimum threshold are not recorded. Results of analysis of AE signals captured during three-point bending fracture tests are introduced in Fig. 2 in the form of the arithmetic mean (obtained from 3 independent measurements) and standard deviations as error bars.
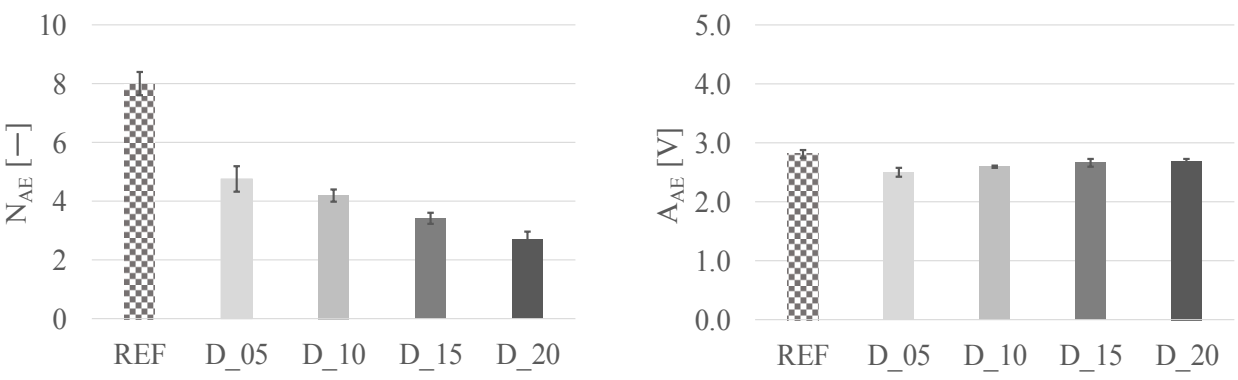

Fig. 2. Determined values (mean \pm standard deviation) of number of AE events (left) and amplitude of AE signals (right) record to ultimate tensile capacity.

Fig. 2 and Fig. 3 present the dependence of a number of $\mathrm{AE}$ events and amplitude of $\mathrm{AE}$ signals on the amount of steel fibres in specimens. The number of AE events and thus the number of micro-cracks created is decreased with the increasing amount of steel fibres, before maximum load. The diagram on the right (Fig. 2) shows that although the number of 
AE events decreased the size of created microcracks is quite uniform. It is probably caused by the properties of the matrix.
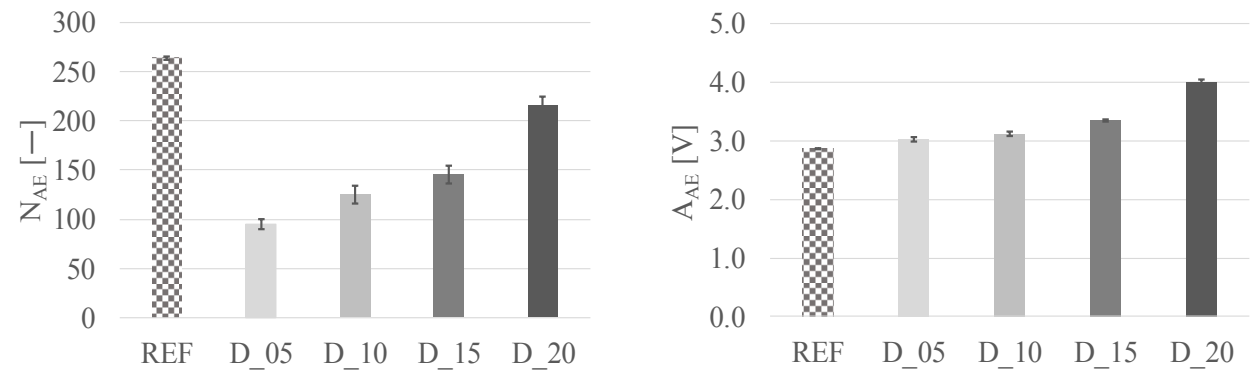

Fig. 3. Determined values (mean \pm standard deviation) of number of AE events (left) and amplitude of AE signals (right) record during the whole measurement.

From the record of the whole measurement it is evident that the number of AE events increased with amount of steel fibres which is, in this case, caused by the pulling the steel fibres out of the matrix. REF specimens have the highest number of AE events which is caused by the total destruction of specimens during three-point bending test. This destruction did not occur at specimens with steel fibres. As can be observed, the amplitude of AE signals increases as the amount of steel fibres in the specimen becomes larger.

\subsection{Mechanical fracture parameters}

The acoustic emission results are accompanied by selected mechanical fracture parameters determined via evaluation of $F-d$ diagrams recorded during three-point bending tests. Mean values and coefficients of variation are introduced in Table 2.

Table 2. Mean values of selected mechanical fracture parameters (coefficient of variation in \%).

\begin{tabular}{|c|c|c|c|c|c|}
\hline Parameter [unit] & REF & D_05 & D_10 & D_15 & D_20 \\
\hline$E[\mathrm{GPa}]$ & $\begin{array}{c}15.1 \\
(4.1)\end{array}$ & $\begin{array}{c}21.1 \\
(10.6)\end{array}$ & $\begin{array}{c}20.3 \\
(13.2)\end{array}$ & $\begin{array}{c}20.0 \\
(9.7)\end{array}$ & $\begin{array}{c}18.4 \\
(22.6)\end{array}$ \\
\hline$K_{I c}\left[\mathrm{MPa} \cdot \mathrm{m}^{1 / 2}\right]$ & $\begin{array}{c}0.843 \\
(8.1)\end{array}$ & $\begin{array}{c}0.821 \\
(16.0)\end{array}$ & $\begin{array}{c}0.971 \\
(10.8)\end{array}$ & $\begin{array}{c}1.170 \\
(10.0)\end{array}$ & $\begin{array}{c}1.304 \\
(25.6)\end{array}$ \\
\hline$G_{F}{ }^{*}\left[\mathrm{~J} / \mathrm{m}^{2}\right]$ & $\begin{array}{c}113.1 \\
(17.7)\end{array}$ & $\begin{array}{c}155.4 \\
(2.3)\end{array}$ & $\begin{array}{c}249.0 \\
(6.6)\end{array}$ & $\begin{array}{c}299.7 \\
(10.0)\end{array}$ & $\begin{array}{c}327.4 \\
(18.5)\end{array}$ \\
\hline$f_{c}[\mathrm{MPa}]$ & $\begin{array}{c}64.9 \\
(1.7)\end{array}$ & $\begin{array}{c}77.1 \\
(10.7)\end{array}$ & $\begin{array}{c}91.2 \\
(2.8)\end{array}$ & $\begin{array}{c}92.9 \\
(2.9)\end{array}$ & $\begin{array}{c}92.1 \\
(2.7)\end{array}$ \\
\hline
\end{tabular}

The modulus of elasticity value increased with the addition of fibres. The highest value was in case of $5 \%$ addition of. Then, values gradually decreased with higher dosage of fibres but the coefficient of variation increased more than twice. This might have been caused by relatively high volume of fibres in matrix, the distribution of which is not uniform. The effective fracture toughness increased with higher dosage of steel fibres, too. The value for D_20 mixture was by 55\% higher compared to the reference one. The most significant increase was observed for specific fracture energy. This parameter increased almost three times in case of the highest fibre dosage. The informative value of compressive strength increased with addition of steel fibres by approximately $40 \%$ if at least $10 \%$ of fibres was added. 


\section{Conclusions}

In this investigation, several experimental tests were carried out on alkali-activated slag with steel fibres specimens loaded up to failure are analysed. Specimens with central notch were subjected to the three-point bending test. During the experiments, the AE technique was used to monitor the progress of the specimens' failure. It is obvious, that different types of damage generate different AE signals. These differences can be related to the amount of fibres in the structure. A small number of cracks generate a small number of events before the failure occurs. This superior performance may be attributed to higher bond properties between fibre and alkali-activated slag mortar. The properties of the AE signals can be linked to the overall fracture behaviour of the materials. The value of all selected mechanical fracture parameters was increased with the addition of fibres to the alkali-activated slag matrix. The addition of fibres improves resistance to crack propagation through the alkali-activated matrix.

This outcome has been achieved with the financial support of the Czech Science Foundation, project No. GA 16-00567S, and the Ministry of Education, Youth and Sports of the Czech Republic under the "National Sustainability Programme I", project No. LO1408 (AdMaS UP).

\section{References}

1. C. Shi, P.V. Krivenko, D. Roy, Alkali-activated cements and concretes (CRC Press, Taylor \& Francis, 2006)

2. F. Puertas, T. Amat, A. Fernandez-Jimenez, T. Vazquez, Cement Concrete Res, 33 (2003)

3. D.J. Hannant, Fiber cements and fiber concretes (John Wiley \& Sons Ltd, 1978)

4. M. Şahmaran, I.Ö. Yaman, Constr Build Mater, 21 (2007)

5. F. Bencardino, L. Rizzuti, G. Spadea, R.N. Swamy, Compos Part B-Eng, 24 (2010)

6. S. Bernal, R.D. Gutierrez, S. Delvasto, E. Rodriguez, Constr Build Mater, 24 (2010)

7. V. Corinaldesi, G. Moriconi, Cement Concrete Res, 34 (2004)

8. Ş. Yazıc1, I.G, V. Tabak, Constr Build Mater, 21 (2007)

9. A. Bentur, Mat Sci Series, 1 (1989)

10. A. Bentur, S. Mindness, Fibre reinforced cementitious composites (E \& FN Spon, 1990)

11. Ch.U. Grosse, M. Ohtsu, Acoustic Emission Testing (Springer, 2008)

12. M. Ohtsu, Mater Sci Res Int, 4 (1998)

13. B.L. Karihaloo, Fracture Mechanics and Structural Concrete (Longman Pub Group, 1995)

14. RILEM Committee FMT 50, Materials and Structures, 18 (1985) 